\title{
Study on establishing a mining group of deposit and an exploration grid pattern for lead - zinc ore in Ban Lim area, Cao Bang province
}

\author{
Khang Quang Luong ${ }^{1,}{ }^{*}$, Hung The Khuong ${ }^{1}$, Tuong Van Nguyen ${ }^{2}$, Thu Thi Le ${ }^{1}$ \\ ${ }^{1}$ Faculty of Geosciences and Geoengineering, Hanoi University of Mining and Geology, Vietnam \\ 2 Dong Bac Geological Division, Cach Mang Thang Tam road, Thai Nguyen City, Thai Nguyen, Vietnam
}

\section{ARTICLE INFO \\ Article history: \\ Received 05 th Feb. 2020 \\ Revised 26 $6^{\text {th }}$ May 2020 \\ Accepted $30^{\text {th }}$ June 2020}

Keywords:

Ban Lim area,

Exploration grid pattern,

Lead-zinc ore,

Mining group.

\section{ABSTRACT}

Ban Lim area in Cao Bang province has proposed a high potential of leadzinc resources, which have occurred in different rocks of geological formation. The paper-based on collecting, synthesizing, and geological processing data. In addition, mathematical methods were also applied to recognize studied objects of the exploration process using a quantitative description. The results how that the lead-zinc orebodies in Ban Lim area mainly occurred in lens-shaped and distributed in layered surfaces of the dolomitized limestone of Coc Xo formation. The average lead-zinc content of the orebodies is in a range from $3.27 \%$ to $8.33 \%$; its coefficient of variation (Vc) is in a range from $13.71 \%$ (evenly) to $137.92 \%$ (very unevenly). Generally, the lead-zinc contents of the orebodies in Ban Lim area mainly comply with the standard normal distribution. The average thicknesses of the orebodies are in a range from $0.92 \mathrm{~m}$ to $6.48 \mathrm{~m}$, its coefficient of variation (Vm) is in the range from $8.7 \%$ (stable) to $132.95 \%$ (very unstable). Quantitative calculation results have shown that Ban Lim lead-zinc deposit belongs to group III of deposits. For the exploration of this type of minerals, it is recommended to use a linear grid pattern. Appropriate exploration grid pattern for the 122 category reserve is $(60 \div 80) m \times(30 \div 40) \mathrm{m}$. These calculated results are well- documented foundations that allow suggesting a mining group of deposit and an exploration grid pattern for lead-zinc ore in Ban Lim area and other leadzinc deposits occurring in similar geological settings.

Copyright (C) 2020 Hanoi University of Mining and Geology. All rights reserved.
${ }^{*}$ Corresponding author

E-mail: luongquangkhang@humg.edu.vn DOI: $10.46326 / J M E S .2020 .61(3) .04$

\section{Introduction}

According to Provisions of the Vietnam Ministry of Natural Resources and Environment (2006), deposits are categorized by their complexity, size, and shape. From this concept, 
mineral deposits can be divided into four groups. Group I: comprised of deposits that have no structural complexity, uniform thickness, and homogeneous grades. They are often large deposits, simple in form, with uniform distribution of minerals. A normal density of drill holes allows the definition of a high level of 121 reserves. Deposits of Group II are more complex in structure, non-uniform thickness, and significant grade variability. They are large deposits with different, sometimes complicated forms and uneven distribution of minerals. Only up to 121 category reserves may be defined with a normal grid of drill holes. Group III consists of deposits that have a highly complex structure, significant variations in thickness, and very uneven grade distribution. These deposits are smaller sized with uneven distribution of minerals. Drill holes can only establish 122 reserves. Finally, Group IV deposits - extremely complex structure, extreme variations in thickness, and grade distribution. They are smaller sized deposits or small pocket deposits with even more complex shapes. Drilling in combination with underground workings is necessary to establish category 122 reserves.

Geological mapping works have revealed several lead-zinc ore deposits in Cao Bang province. However, most of these deposits are proposed as small to medium in size, excepted for Ban Lim area that is evaluated over prospective (Do Quoc Binh, 2004; Nguyen Van Phu, 2019). Up to present, there are no systematically researchs on geochemical characteristics, mineralization processes as well as the mining exploration group with adequate grids for the lead-zinc ore type in the area. Therefore, the results of geological data processing and mathematical methods for Ban Lim area presented here will play an important role for mineral exploration and mining in the future.

\section{General geological features of Ban Lim area, Cao Bang province}

The lithology of Ban Lim area is composed mainly of carbonate intercalated with gray, light gray to dark-gray terrigenous sedimentary rocks that were suggested as early Devonian age named Coc Xo formation (Nguyen Van Phu, 2019). In the center of Ban Lim area, effusive rocks of felsic and rhyolite (undefined age) are exposed in lensshaped, extending in the northwest-southeast trending (Figure 1). Quaternary sediment distributes along the river and Ban Lim valley.

Having studied the structure of the Ban Lim area, the previous work has proved a monoclinal structure extends in a northwest-southeast direction (Phung Quoc Tri, 2013). Three fault systems also have been mapped in the area (Nguyen Van Phu, 2019) which are northwestsoutheast, northeast-southwest, and near a westeast trending system of which the northwestsoutheast fault system has been supported as the major faults and controlled the main structure of Ban Lim area (Nguyen Van Phu, 2019). Most of the lead-zinc orebodies discovered in Ban Lim area are controlled by this fault system (Phung Quoc Tri, 2013; Nguyen Van Phu, 2019). The northeastsouthwest and west-east fault systems are younger and displaced the orebodies that make the area complicated.

\section{Methods}

Establishing a mining group of deposit and an exploration grid within a study area can be characterized by statistical measures and properties describing the pattern, as well as by indicators of more local properties of the orebodies as shape, morphology, and structure. The former can be described by a series of summary statistics providing information on the morphological and structural orebodies. Estimation of average mineral deposit parameters has been extensively used in quantitative mineral resource assessments to estimate numbers of exploration works in a study area based on statistical methods and the theory of random functions (Wellmer, 1998). In contrast, methods for establishing an exploration grid pattern have rarely been applied to investigate mineral deposit patterns (Saikia \& Sarkar, 2006).

On the combination of geological data being collected, synthesized, and processed from previous documents, the authors have applied geomathematical methods to improve the efficiency of evaluation of lead-zinc mineralization characteristics in Ban Lim area.

\subsection{Establishing a mining group of deposit}




\subsubsection{One-dimensional statistical mechanics model}

This method is used in processing geochemical data for the descriptive statistical distribution of geological parameters such as compositions, thickness, technical properties, and physical parameters of orebodies. The results are used to determine the average value, variance, coefficient of variation of geological parameters. This would ensure process efficiency as well as truthfulness, and non-error in data processing and lending to ensure reliability. From the probability distribution function that allows determining the probability of random numbers appearing in the arbitrary selection range, the method provides a detailed content in Wellmer (1998), Luu Cong Tri (2020).

\subsubsection{Morphological and structural orebodies}

Ore-bearing coefficients (Kp): The ore-bearing coefficient is determined according to the thickness, area, and length of an orebody.

By calculating the orebody thickness:

$$
K_{p}^{m}=\frac{\sum_{i=1}^{N} m_{i}}{\sum_{i=1}^{N} M_{i}}
$$

where $m_{i}$ - thickness of payable ore, which is determined in the $i$-th exploration work; $M_{i}$ thickness of lead - zinc ore bearing rock layer; $N$ number of exploration projects.

By calculating the ore area:

$$
K_{p}^{S}=\frac{\sum_{i=1}^{N} S_{p}}{S}
$$

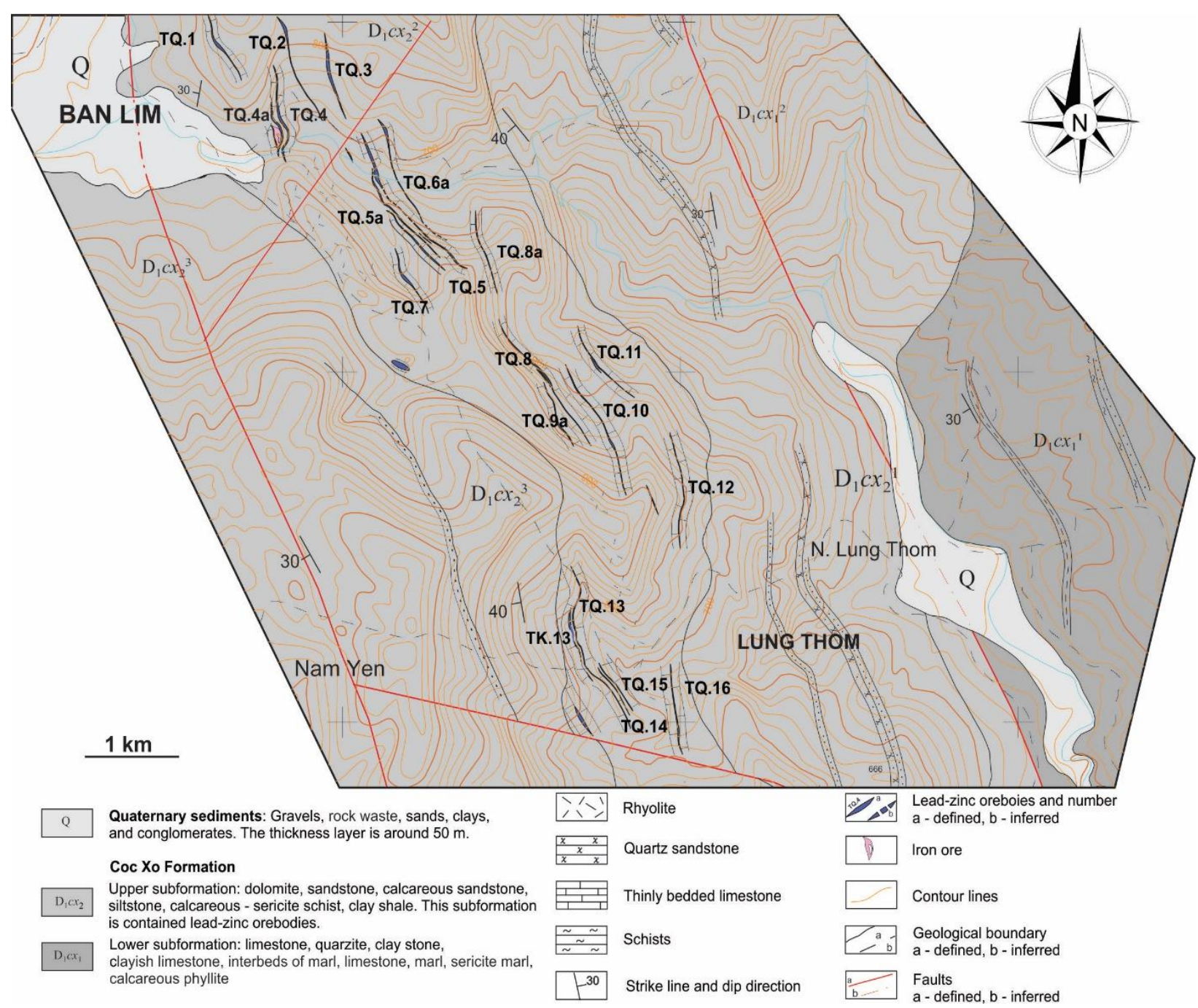

Figure 1. Simplified geological map of Ban Lim area, Cao Bang province (modified from Nguyen Van Phu et al., 2019). 
where $\sum_{i=1}^{N} S_{p}$ - total orebodies area limit in the exploration region; $\mathrm{N}$ - number of orebodies; $\mathrm{S}$ - the area of the exploration object.

By calculating the ore piece:

$$
K_{P}^{L}=\frac{\sum_{i=1}^{N} L_{P}}{\sum_{i=1}^{N} L_{c}}
$$

where $\sum_{i=1}^{N} L_{P^{-}}$total length of orebodies; $\sum_{i=1}^{N} L_{C^{-}}$total general length of the exploration lines.

Coefficients of broken ore $\left(K_{n p}\right)$ is determined by the formula:

$$
K_{n p}=\frac{i}{K_{p}^{m}}
$$

with $i$ - number of broken ore is determined by exploration lines section; $K_{p}^{m}$ - ore-bearing coefficients.

Coefficients of morphological anisotropy $(\lambda)$ of orebodies on the mapping are determined by:

$$
\lambda=\frac{A}{B}
$$

with A - orebody thickness is determined in mapping; B - orebody width is determined in mapping.

Coefficients of the ore dressing $(\beta)$ are determined by the formula:

$$
\beta=\frac{C_{t b}}{C_{C N}}
$$

with $\mathrm{C}_{\mathrm{tb}}-$ mean $\mathrm{Pb}+\mathrm{Zn}$ contents of payable orebodies; $\mathrm{C}_{\mathrm{CN}}$ - selected minimum economic content of ore.

Boundary modules are determined on the basis by comparing the actual circumference and circumference of the orebody in geometric form. The complexity degree of the orebody boundary is determined by the formula:

$$
M_{K}=\frac{e \varphi}{4.7 a+1.5 \frac{L \varphi}{a}-1.77 \sqrt{L \varphi}}
$$

In which: a - half of the longest boundary (m); $\mathrm{L} \phi$ - the perimeter of the orebody is converted to an ellipse; e $\phi$ - actual circumference of the orebody.

Orebody shaped index $(\phi)$ is calculated as:

$$
\varphi=\frac{V M_{K}}{K_{c c}}
$$

in which, $\mathrm{V}$ - coefficient of variation of payable orebody thickness (\%); $\mathrm{K}_{\mathrm{cc}}$ - coefficient of complexity orebody structure,

$$
K_{c c}=1-\frac{m_{k} n_{k}}{m_{q} n_{q}}
$$

with $m_{k}$ - total mean thickness of intercalated layers in orebody; $n_{k}$ - total number of intercalated layers in orebody; $\mathrm{m}_{\mathrm{q}}$ - total mean thickness of ore beds; $n_{q}$ - total number of ore beds.

\subsection{Establishing an exploration grid pattern}

\subsubsection{Statistical methods}

The given area of estimation reserves, the errors of estimated metal reserves are determined as formulas:

$$
\begin{gathered}
\Delta_{p}=\sqrt{\Delta_{m}^{2}+\Delta_{c}^{2}+\Delta_{d}^{2}+\Delta_{s}^{2}} \\
\Delta_{x}=\frac{t \cdot V_{x}}{\sqrt{N}} \\
\Delta_{S}=\frac{S_{2}}{4 S_{1}} \cdot 100 \%
\end{gathered}
$$

where $\Delta_{m}, \Delta_{c}, \Delta_{d}, \Delta_{s}$ - relative standard errors of mean thickness, mean content, orebody area, and mean bulk density of ore; $S_{1}$ - interpolated orebody area; $S_{2}$ - extrapolated orebody area.

Relative standard errors of bulk density $\left(\Delta_{d}\right)$ are common, very least errors, and skipping. Exploratory data analysis of lead - zinc contents are generated gross errors and random, and it is lending to mean contents are determined as:

$$
\Delta_{c^{\prime}}=\sqrt{\Delta_{c}^{2}+\Delta_{p t}^{2}}
$$

with $\Delta_{p t}$ - random errors in sample analysis.

Estimation for the density of exploration grid by mathematical statistics. Kazdan (1977) declared that exploration results meet reliability requirements when an error of the reserve parameters.

$$
\sum \Delta=\sqrt{\Delta^{2}{ }_{m}+\Delta^{2}{ }_{c}+\Delta^{2}{ }_{d}+\Delta^{2}{ }_{s}} \leq \Delta_{c p}
$$


For group III deposits, to meet the requirement of calculating the 122 category reserves to ensure safety, it is necessary to select the relative reserves of allowable reserve according to the current regulations in the range of $30 \div 50 \%$. Therefore, the number of exploration works that are necessary to control orebodies can be determined by the formula:

$$
N \geq \frac{\left(V_{m}^{2}+V_{c}^{2}\right) t^{2}}{\Delta^{2} c p}
$$

or following point reserves:

$$
N \geq \frac{V^{2}{ }^{2} \cdot t^{2}}{\Delta^{2} c p}
$$

where, $V_{m}, V_{c}, V_{q}$ - coefficient of variation in thickness, contents, and point reserves of estimated orebodies; $\Delta_{c p}$ - permissible error $(30 \div$ $50 \%) ; t$ - probability factor $(t=2$ corresponding to $P=0,95)$. In fact, an exploration often encounters orebody, which is often distorted, many researchers recommend adding distortion coefficients to the orebody and taking the value of 0.15 . Therefore, the number of specific works is $1.15 \mathrm{~N}$.

Pogrebiski (1973) summed up that when mineral deposits have a coefficient of variations in thickness and content over $80 \%$, the number of works calculated by statistical methods are often larger than reality. Conversely, if their coefficient of variations is less than $40 \%$, the number of calculation works will smaller. In the case of changes in the coefficient of variation in the range of $60 \div 80 \%$, the method usually gives good results. Therefore, the density of exploration grid $\left(S_{o}\right)$ is calculated by the formula:

$$
S_{0}=\frac{S}{N}
$$

with $S_{o}=a \times b ; a=0.93 \sqrt{S_{o}} ; b=1.07 \sqrt{S_{o}} ;$ where, $S$ - orebody area; $N$ - number of exploration works; $a$-strike line; $b$ - dip direction.

\subsubsection{Applied methods of the theory of random functions}

The stable random function is featured by correlation function $K_{x}(h)$, depending on range, observed direction, and correlation function of the norm - $R(h)$. The formula determines the correlation function:

$$
\begin{aligned}
& K_{x}(\vec{h}) \\
& =\frac{1}{N-h} \sum_{i=1}^{N-h}\left[f\left(x_{i}\right)-E(X)\right]\left[f\left(x_{i t h}\right)-E(X)\right]
\end{aligned}
$$

The correlation function of the norm is determined by the formula:

$$
R(h)=\frac{K_{x}(\vec{h})}{\sigma_{x}^{2}}
$$

To determine the influence zone size $(H)$ or determined domain that allows interpolation, oscillation, and random transformation, the authors carry out the construction of correlation plots.

$R_{(h)}^{*}=e^{-\alpha h}$ with $\alpha$ - coefficient of variation in variability zone; $h$ - observed range.

Constructed plots of function:

$$
2 \sigma_{r}=\frac{2\left[1-R_{h}^{*}\right]}{\sqrt{N}}
$$

Anisotropy coefficient (I) is defined as:

$$
I=\frac{H_{h d}}{H_{d p}}
$$

where $H_{d p}$ - size of the influence zone determined in the strike line; $H_{h d}$ - size of the influence zone defined in dip direction.

The density of exploration grid $\left(S_{0}\right)$ is calculated by the formula:

$$
S_{o}=H_{h d} \times H_{N}
$$

Number of required exploration works for assessment of orebody is defined as:

$$
N=\frac{S}{S_{0}}
$$

If coordinates $\left(x_{i}, y_{i}\right)$ of the collection point need to convert to coordinates $\left(x_{k}, y_{k}\right)$ of the grid cell, this conversion is done according to the formula:

$$
Z_{k}=\frac{\sum_{i=1}^{n} \frac{Z i}{D i}}{\sum_{i=1}^{n} \frac{1}{D i}}
$$

Where $Z_{k}$ - average value of the study parameter at $k$ point of the established base cell; $D_{i k}$ - distance from point $k$ to the closest point of $Z_{i}$ value. 


\section{Results and discussions}

\subsection{Characteristics of lead-zinc bodies}

Rooted from previous synthetic documents (Do Quoc Binh, 2004; Phung Quoc Tri, 2013; Nguyen Van Phu, 2019), and incorporating additional research materials, the authors allow further clarification of the distribution characteristics, structural and morphological characteristics, relationships and exist at a depth of orebodies in the study area.

The results of this study indicate that the lead-zinc bodies are mainly lens-shaped, and bulge along the strike line of the orebody. Ore exposures are complicated and changing both quantity and shape very much. Lead-zinc ores have occurred in associated with thick - to medium-bedded dolomitized limestone. Ore compositions are fairly evenly distributed along the strike line and dip direction of orebodies. Ore compositions are commonly an irregular lattice that is distributed in the layered surface of dolomitized limestone. Orebody dip to southwestward with dip angle is varying from $35^{\circ}$ to $45^{\circ}$. The typical results of major orebodies are listed in Table 1.

\subsection{Estimation of exploration group for lead- zinc deposit in Ban Lim area}
4.2.1. Statistical characteristics of lead-zinc orebody parameters

Statistical treatment of content and thickness of the lead-zinc orebody in Ban Lim area is listed in Table 2.

Results from Table 2 show that in all orebodies, the mean lead-zinc content is in a range from $3.27 \%$ to $8.33 \%$, its coefficient of variation $(V c)$ is in the range from $13.71 \%$ (evenly) to $137.92 \%$ (very unevenly).

Table 1. General characteristics of lead-zinc bodies in Ban Lim area.

\begin{tabular}{|c|c|c|c|c|c|c|}
\hline \multirow{2}{*}{ No } & \multirow{2}{*}{$\begin{array}{c}\text { Ore } \\
\text { bodies }\end{array}$} & $\begin{array}{c}\text { Extend along with } \\
\text { strike line }\end{array}$ & $\begin{array}{c}\text { Extend along with dip } \\
\text { direction (from-to) }\end{array}$ & $\begin{array}{c}\text { Average } \\
\text { thickness }\end{array}$ & Shape & $\begin{array}{c}\text { Strike/dip } \\
\text { (degree) }\end{array}$ \\
\hline 1 & TQ.1 & 130 & $30-40$ & 0.99 & lens-shaped & $240 / 30$ \\
\hline 2 & TQ.2 & 180 & $40-55$ & 1.55 & lens-shaped & $240 / 48$ \\
\hline 3 & TQ.3 & 180 & 15 & 3.18 & lens-shaped & $250 / 15$ \\
\hline 4 & TQ.4 & 170 & 45 & 6.15 & lens-shaped & $230-240 / 41$ \\
\hline 5 & TQ.4a & 170 & $35-45$ & 6.48 & lens-shaped & $230-240 / 35$ \\
\hline 6 & TQ.5 & 135 & 40 & 5.98 & lens-shaped & $235-240 / 41$ \\
\hline 7 & TQ.5a & 135 & $40-45$ & 3.80 & lens-shaped & $230 / 36$ \\
\hline 8 & TQ.6 & 145 & $40-45$ & 3.42 & lens-shaped & $240 / 40$ \\
\hline 9 & TQ.6a & 155 & $30-50$ & 4.51 & lens-shaped & $240 / 37$ \\
\hline 10 & TQ.7 & 145 & $35-40$ & 2.60 & lens-shaped & $240 / 41$ \\
\hline 11 & TQ.8 & 145 & $35-40$ & 1.72 & lens-shaped & $230 / 42$ \\
\hline 12 & TQ.8a & 140 & 45 & 1.65 & lens-shaped & $240 / 43$ \\
\hline 13 & TQ.9 & 140 & 45 & 3.45 & lens-shaped & $230 / 42$ \\
\hline 14 & TQ.10 & 140 & 45 & 1.46 & lens-shaped & $240 / 40$ \\
\hline 15 & TQ.11 & 150 & 45 & 1.25 & lens-shaped & $230 / 50$ \\
\hline 16 & TQ.12 & 140 & $35-50$ & 1.35 & lens-shaped & $250 / 38$ \\
\hline 17 & TQ.13 & 170 & $35-45$ & 2.62 & lens-shaped & $250-280 / 40$ \\
\hline 18 & TQ.13a & 160 & $40-50$ & 3.01 & lens-shaped & $250 / 45$ \\
\hline 19 & TQ.14 & 160 & $40-50$ & 3.43 & lens-shaped & $250 / 45$ \\
\hline 20 & TQ.15 & 145 & 45 & 0.92 & lens-shaped & $250 / 43$ \\
\hline 21 & TQ.16 & 145 & 45 & 1.83 & lens-shaped & $250 / 40$ \\
\hline
\end{tabular}


Table 2. Statistical characteristics of lead-zinc content of the orebodies.

\begin{tabular}{|c|c|c|c|c|c|c|}
\hline \multirow{2}{*}{ Orebody } & \multicolumn{5}{|c|}{$\mathrm{Pb}+\mathrm{Zn}$ contents (\%) } & \multirow{2}{*}{ Distribution pattern } \\
\cline { 2 - 6 } & $\begin{array}{c}\text { Average } \\
\text { content }\end{array}$ & Variance $\left(\sigma^{2}\right)$ & $\begin{array}{c}\text { Coefficient of } \\
\text { variation }\left(V_{c}\right)\end{array}$ & $t_{A}$ & $t_{\mathrm{E}}$ & \\
\hline TQ.1 & 1.09 & 0.18 & 39.06 & 1.93 & 1.65 & Lognormal standard \\
\hline TQ.2 & 5.55 & 11.35 & 60.72 & -0.38 & -1.13 & Normal standard \\
\hline TQ.3 & 5.81 & 0.63 & 13.71 & 0.25 & 0.44 & Normal standard \\
\hline TQ.4 & 5.17 & 9.61 & 59.92 & 1.82 & 1.97 & Normal standard \\
\hline TQ.4a & 4.40 & 4.29 & 47.09 & 1.42 & 1.19 & Normal standard \\
\hline TQ.5 & 4.76 & 1.74 & 27.71 & -0.36 & 0.06 & Normal standard \\
\hline TQ.5a & 3.74 & 3.18 & 47.65 & 0.94 & -0.13 & Normal standard \\
\hline TQ.6 & 1.48 & 0.33 & 38.67 & 0.93 & -0.6 & Lognormal standard \\
\hline TQ.6a & 3.95 & 2.61 & 40.89 & -0.02 & -1.32 & Normal standard \\
\hline TQ.7 & 5.65 & 15.66 & 70.03 & 0.88 & -0.92 & Normal standard \\
\hline TQ.8 & 5.17 & 2.24 & 28.94 & -0.85 & 0.47 & Normal standard \\
\hline TQ.8a & 8.20 & 26.28 & 62.53 & 1.25 & 0.85 & Normal standard \\
\hline TQ.9 & 4.13 & 3.89 & 47.74 & 1.13 & 0.83 & Normal standard \\
\hline TQ.10 & 6.85 & 15.51 & 57.52 & 1.82 & 1.27 & Normal standard \\
\hline TQ.11 & 4.87 & 7.82 & 57.48 & 1.48 & 1.33 & Normal standard \\
\hline TQ.12 & 4.70 & 7.00 & 56.31 & 0.30 & -1.06 & Normal standard \\
\hline TQ.13 & 8.32 & 35.27 & 71.34 & 1.88 & -0.12 & Normal standard \\
\hline TQ.13a & 6.96 & 92.26 & 137.92 & 2.70 & 3.44 & Normal standard \\
\hline TQ.14 & 6.07 & 12.59 & 58.48 & 0.70 & 0.81 & Normal standard \\
\hline TQ.15 & 8.33 & 25.32 & 60.42 & 1.30 & 1.28 & Normal standard \\
\hline TQ.16 & 5.55 & 4.79 & 39.41 & 1.06 & 0.60 & Normal standard \\
\hline & & & & & & \\
\hline
\end{tabular}

On the whole, the lead-zinc contents of the orebodies in Ban Lim area are mainly complied with standard normal distribution, except for orebodies of TQ.1 and TQ.6 are lognormal distribution.

As mentioned in Table 3, an average thickness of the lead-zinc orebodies varies from $0.92 \mathrm{~m}$ to $6.48 \mathrm{~m}$, its coefficient of variation $\left(\mathrm{V}_{\mathrm{m}}\right)$ is in the range of $8.7 \div 132.95 \%$, their distributions belong to stable to very unstable. All orebody thicknesses mainly comply with the standard normal distribution.

\subsubsection{Characteristics of continuous mineralization}

Features of continuous mineralization are one of the main factors that influence the degree of ease of available exploration geology. Therefore, a quantitative study of the continuity of lead-zinc ore mineralization by applying formulas (1), (2), and (3) are listed below.

For investigated lead-zinc orebodies, the authors are going to estimate the degree of broken ore, morphological anisotropy, and coefficients of ore dressing by applying formulas (4), (5), and (6).

The results presented in Table 4 point out that lead-zinc ore mineralization is of discontinuous and continuous types, their coefficients of broken ore are complicated, especially in the orebody TQ.5 (Knp=108.11). Major lead-zinc bodies are commonly anisotropy shape (as seen in the TQ.3, TQ.4, TQ.4a, TQ.5, TQ.5a, TQ.6, TQ.6a, TQ.7, TQ.9, TQ13, TQ.14), except for the orebodies TQ.1, TQ.2, TQ.6, TQ.7, TQ.8, TQ.8a, TQ.10, TQ.11, TQ.12, TQ.13a, TQ.15, and TQ.16. In most cases, lead-zinc contents belong to the base and medium; its coefficients of ore dressing are in a range from 0.94 (TQ.1) to 2.38 (TQ.13).

\subsubsection{Complexity degree of orebody boundary module and orebody shaped index}

The shapes, strike, dip formats, and complexity degree of structural orebodies have 
been estimated by applying (7), (8), and (9). Calculated results of the complexity degree of the orebody boundary module and orebody shaped index are listed in Table 5.

Table 5 shows the complexity and shaped index of lead-zinc orebodies that vary from simple to complex. In Ban Lim area, research results on the quantitative changes of lead-zinc ore mineralization point out the thickness of orebodies is from medium to small size, its shape changes from relatively complicated to more complicated. Coefficients of thickness variation of orebodies are stable to unstable types with discontinuous mineralization. Lead-zinc contents of Ban Lim deposit are even to unevenly distribution: they also belong to the base and medium contents and covered by burden. Orebodies are relatively gentle dips. Found from the characteristics of Ban Lim lead-zinc orebodies, and inferred from the documents of Vietnam Ministry of Natural Resources and Environment (06/2006/QĐ-BTNMT), the authors, therefore, categorize Ban Lim lead-zinc deposit to group III.

4.2.4. Definition of exploration grid pattern for Ban Lim lead-zinc deposit

The definition of a rational exploration grid, also known as optimization of the exploration grid, is done on the basis of the documents of exploration geological parameters. They are important to consider explorer objects and depend on mining-geological structure characteristics. In most cases, point reserves (meters, \%) can be used as the key of geological parameters. If the thickness or important elements of orebodies are the largest variations, the selection of the exploration grid will be depended on the characteristics of the largest orebody.

* Evaluating the effectiveness of exploration system

Relative errors of lead-zinc bodies are calculated by equations (10), (11), (12), and (13). The results are listed in Table 6.

Table 3. Statistical characteristics of lead-zinc orebody thicknesses.

\begin{tabular}{|c|c|c|c|c|c|c|}
\hline \multirow{2}{*}{ Orebody } & \multicolumn{5}{|c|}{ True thickness parameters (meter) } & \multirow{2}{*}{ Distribution pattern } \\
\cline { 2 - 6 } & Average & $\begin{array}{c}\text { Variance } \\
\left(\sigma^{2}\right)\end{array}$ & $\begin{array}{c}\text { Coefficient of } \\
\text { variation }\left(V_{m}\right)\end{array}$ & $t_{A}$ & $t_{E}$ & \\
\hline TQ.1 & 0.99 & 0.03 & 18.90 & 1.52 & 1.77 & Normal standard \\
\hline TQ.2 & 1.55 & 1.78 & 86.11 & 2.19 & 2.44 & Normal standard \\
\hline TQ.3 & 3.18 & 3.82 & 61.44 & 1.28 & 0.94 & Normal standard \\
\hline TQ.4 & 6.15 & 32.99 & 93.37 & 1.23 & $(0.48)$ & Normal standard \\
\hline TQ.4a & 6.48 & 37.25 & 94.22 & 0.76 & $(1.08)$ & Normal standard \\
\hline TQ.5 & 5.98 & 28.21 & 88.81 & 2.06 & $(0.14)$ & Normal standard \\
\hline TQ.5a & 3.80 & 3.99 & 52.58 & 0.17 & $(0.67)$ & Normal standard \\
\hline TQ.6 & 3.42 & 4.98 & 65.25 & 1.92 & 0.85 & Normal standard \\
\hline TQ.6a & 4.51 & 15.51 & 87.42 & 0.34 & $(1.09)$ & Normal standard \\
\hline TQ.7 & 2.60 & 2.34 & 58.78 & $0.03)$ & $(1.38)$ & Normal standard \\
\hline TQ.8 & 1.72 & 0.12 & 20.45 & 1.23 & 1.28 & Normal standard \\
\hline TQ.8a & 1.65 & 0.32 & 34.25 & 0.24 & 0.62 & Normal standard \\
\hline TQ.9 & 0.80 & 0.89 & 117.23 & 0.79 & -0.24 & Lognormal standard \\
\hline TQ.10 & 1.46 & 0.18 & 29.02 & 0.49 & $(0.57)$ & Normal standard \\
\hline TQ.11 & 1.25 & 0.43 & 52.50 & 0.43 & $(0.74)$ & Normal standard \\
\hline TQ.12 & 1.35 & 0.06 & 17.69 & $(0.36)$ & $(1.06)$ & Normal standard \\
\hline TQ.13 & 2.62 & 7.48 & 104.34 & 4.26 & 5.81 & Normal standard \\
\hline TQ.13a & 3.01 & 1.22 & 36.75 & 0.61 & $(0.15)$ & Normal standard \\
\hline TQ.14 & 3.43 & 20.80 & 132.95 & 1.94 & 2.11 & Normal standard \\
\hline TQ.15 & 0.92 & 0.01 & 8.70 & $0.64)$ & $(0.14)$ & Normal standard \\
\hline TQ.16 & 1.83 & 0.25 & 27.13 & 1.42 & 1.24 & Normal standard \\
\hline
\end{tabular}


Table 4. Calculated results of lead-zinc ore-bearing coefficients.

\begin{tabular}{|c|c|c|c|c|}
\hline No & Orebody & Orebody thickness $\left(K_{p}{ }^{m}\right)$ & Ore area $\left(K_{p}{ }^{S}\right)$ & Ore piece $\left(K_{p}{ }^{L}\right)$ \\
\hline 1 & TQ.1 & 0.022 & 0.0004 & 0.021 \\
\hline 2 & TQ.2 & 0.023 & 0.0001 & 0.011 \\
\hline 3 & TQ.3 & 0.032 & 0.0002 & 0.010 \\
\hline 4 & TQ.4 & 0.108 & 0.0003 & 0.014 \\
\hline 5 & TQ.4a & 0.130 & 0.0002 & 0.007 \\
\hline 6 & TQ.5 & 0.009 & 0.0003 & 0.014 \\
\hline 7 & TQ.5a & 0.114 & 0.0002 & 0.010 \\
\hline 8 & TQ.6 & 0.222 & 0.0002 & 0.021 \\
\hline 9 & TQ.6a & 0.068 & 0.0002 & 0.013 \\
\hline 10 & TQ.7 & 0.039 & 0.0001 & 0.010 \\
\hline 11 & TQ.8 & 0.026 & 0.0001 & 0.010 \\
\hline 12 & TQ.8a & 0.016 & 0.0002 & 0.011 \\
\hline 13 & TQ.9 & 0.095 & 0.0003 & 0.013 \\
\hline 14 & TQ.10 & 0.029 & 0.0001 & 0.014 \\
\hline 15 & TQ.11 & 0.019 & 0.0001 & 0.010 \\
\hline 16 & TQ.12 & 0.010 & 0.0003 & 0.014 \\
\hline 17 & TQ.13 & 0.111 & 0.0002 & 0.020 \\
\hline 18 & TQ.13a & 0.053 & 0.0001 & 0.009 \\
\hline 19 & TQ.14 & 0.043 & 0.0001 & 0.006 \\
\hline 20 & TQ.15 & 0.011 & 0.011 \\
\hline 21 & TQ.16 & 0.018 & 0.010 \\
\hline
\end{tabular}

Table 5. Complexity degree of orebody boundary module and orebody shaped index.

\begin{tabular}{|c|c|c|c|c|c|}
\hline No & Orebody & Area (square meter) & Orebody boundary & Complexity degree & Shaped index \\
\hline 1 & TQ.1 & $1,386.00$ & $1,053.00$ & 0.94 & 0.021 \\
\hline 2 & TQ.2 & 482.40 & 622.60 & 1.12 & 0.026 \\
\hline 3 & TQ.3 & 778.60 & 478.40 & 0.94 & 0.030 \\
\hline 4 & TQ.4 & $1,114.00$ & 589.70 & 0.82 & 0.103 \\
\hline 5 & TQ.4a & 661.50 & 363.30 & 0.97 & 0.126 \\
\hline 6 & TQ.5 & $1,080.00$ & 814.30 & 1.10 & 0.019 \\
\hline 7 & TQ.5a & 771.60 & 607.40 & 1.19 & 0.136 \\
\hline 8 & TQ.6 & $1,762,00$ & $1,023.00$ & 0.91 & 0.202 \\
\hline 9 & TQ.6a & 774.60 & 697.80 & 1.04 & 0.070 \\
\hline 10 & TQ.7 & 679.20 & 436.50 & 0.82 & 0.032 \\
\hline 11 & TQ.8 & 307.50 & 501.70 & 0.94 & 0.024 \\
\hline 12 & TQ.8a & 475.20 & 525.50 & 0.91 & 0.015 \\
\hline 13 & TQ.9 & 562.60 & 717.20 & 1.07 & 0.131 \\
\hline 14 & TQ.10 & 924.50 & 887.70 & 1.20 & 0.035 \\
\hline 15 & TQ.11 & 393.30 & 544.70 & 1.07 & 0.020 \\
\hline 16 & TQ.12 & 471.30 & 683.60 & 0.96 & 0.010 \\
\hline 17 & TQ.13 & 939.10 & $1,059.00$ & 0.98 & 0.155 \\
\hline 18 & TQ.13a & 711.30 & 447.40 & 0.92 & 0.048 \\
\hline 19 & TQ.14 & 268.60 & 335.90 & 1.02 & 0.059 \\
\hline 20 & TQ.15 & 266.60 & 395.70 & 0.71 & 0.008 \\
\hline 21 & TQ.16 & 549.30 & 523.20 & 0.98 & 0.018 \\
\hline
\end{tabular}


Table 6. Relative errors of the lead-zinc reserve of orebodies.

\begin{tabular}{|c|c|c|c|c|c|}
\hline \multirow{2}{*}{ No } & \multirow{2}{*}{ Ore bodies } & \multicolumn{4}{|c|}{ Relative errors (\%), $t=2$} \\
\cline { 3 - 6 } & & $\Delta_{s}$ & $\Delta_{m}$ & $\Delta_{c}$ & $\Delta_{p}$ \\
\hline 1 & TQ.1 & 1.34 & 70.58 & 45.30 & 83.87 \\
\hline 2 & TQ.2 & 0.66 & 70.31 & 49.57 & 86.03 \\
\hline 3 & TQ.3 & 2.92 & 61.44 & 13.71 & 63.02 \\
\hline 4 & TQ.4 & 2.45 & 12.60 & 36.69 & 38.87 \\
\hline 5 & TQ.4a & 0.79 & 66.63 & 33.30 & 74.49 \\
\hline 6 & TQ.5 & 1.27 & 38.76 & 12.09 & 40.62 \\
\hline 7 & TQ.5a & 0.73 & 30.36 & 27.51 & 40.98 \\
\hline 8 & TQ.6 & 1.41 & 25.59 & 25.09 & 35.87 \\
\hline 9 & TQ.6a & 1.08 & 71.38 & 33.39 & 78.81 \\
\hline 10 & TQ.7 & 0.64 & 16.70 & 23.63 & 28.94 \\
\hline 11 & TQ.8 & 1.14 & 47.99 & 57.18 & 74.66 \\
\hline 12 & TQ.8a & - & 34.25 & 62.53 & - \\
\hline 13 & TQ.9 & 1.10 & 20.52 & 40.68 & 45.57 \\
\hline 14 & TQ.10 & 0.83 & 67.59 & 28.79 & 73.47 \\
\hline 15 & TQ.11 & 0.66 & 42.86 & 46.93 & 63.56 \\
\hline 16 & TQ.12 & 0.68 & 20.42 & 65.02 & 68.15 \\
\hline 17 & TQ.13 & 0.64 & 27.13 & 39.41 & 47.85 \\
\hline 18 & TQ.14 & - & 118.91 & 52.31 & - \\
\hline 19 & TQ.15 & 0.27 & 7.78 & 54.04 & 54.60 \\
\hline 20 & TQ.16 & 0.67 & 50.61 & 34.61 & 61.31 \\
\hline
\end{tabular}

Table 6 shows the lead-zinc reserve of orebodies (TQ.4, TQ.4A, TQ.5, TQ.5A, TQ.6, TQ.7, TQ.9, TQ.9A, TQ.13) that have the error of less than $50 \%$, calculated in accordance with category 122 reserves. The other ones have the error higher than $50 \%$ stratified category 333 resources. Therefore, the exploration grid pattern has been constructed for lead-zinc ore of Ban Lim deposit to meet the calculation of category 122 reserves and natural category 333 resources that is standardized by the Vietnam Ministry of Natural Resources and Environment (2006).

\section{* Density estimation for exploration grid}

The density of the exploration grid is estimated by formulas (14), (15), (15a\&b), and its calculated results are presented in Table 7.

Calculated results show that the exploration grid of lead-zinc deposit is recommended to use a linear grid. The line spacing is selected to be $80 \mathrm{~m}$ or even better $70 \mathrm{~m}$, and the spacing between the points to be $45 \mathrm{~m}$ or even better $40 \mathrm{~m}$. The number of exploration works varies from $303 \div 357$ works $/ \mathrm{km}^{2}$.

$*$ The theory of stable random functions
Geological parameters of the orebody have a special relationship that is closely related to the distance between exploration works. From those properties, selecting the spacing density of works is a very important issue of a rational exploration grid. Since the exploration conditions (density of observation points, outcrops, and exploration works) are not evenly distributed over a certain geometric grid, it is necessary to convert the actual collected value to each point of the base grid cells for each region by the formula (19). The line spacing is selected to be $80 \mathrm{~m}$, and the spacing between the points is $40 \mathrm{~m}$.

Based on the original and converted documents, to ensure accuracy of the method, the authors carry out the calculation of the autocorrelation radius $R(h)$ following strike line and dip directions for content parameters of orebodies TQ.5, TQ.6 and TQ.13, as they are the biggest ones in the study area.

After establishing the experimental autocorrelation radius $R(h)$, formulas (16), (17) and (18) are applied to conduct modeling; its meaning is induction experimental lines $R(h)$ to theoretical line $R^{*}(h)$, constructs plots and 
calculated size of influence zone $(H)$ determined following strike line and dip direction (Figures 2, $3 \& 4)$.

The obtained results showed that the line spacing is selected to be $70 \mathrm{~m}$ or even better of 60 $\mathrm{m}$, and the spacing between the points to be $35 \mathrm{~m}$ or even better of $30 \mathrm{~m}$. The number of exploration works varies from $420 \div 556$ works $/ \mathrm{km}^{2}$.

Combining calculated results between the statistical and stable random methods allows the detected exploration grid for reserve level 122 , the line spacing is selected to be $60 \div 80 \mathrm{~m}$, and the spacing between the points to be $30 \div 40$ m (Table 9).

Table 7. The density of exploration grid based on the statistical method.

\begin{tabular}{|c|c|c|c|c|c|}
\hline \multirow{2}{*}{ No } & \multirow{2}{*}{ Orebody } & \multicolumn{2}{|c|}{ Distance (meter) } & \multirow{2}{*}{$\begin{array}{l}\text { Density (square } \\
\text { meter) }\end{array}$} & \multirow{2}{*}{$\begin{array}{c}\text { Number of exploration } \\
\text { works } / \mathrm{km}^{2}\end{array}$} \\
\hline & & a - strike line & b-dip direction & & \\
\hline 1 & TQ.4 & 70 & 40 & 2800 & 357 \\
\hline 2 & TQ.5 & 75 & 44 & 3300 & 303 \\
\hline 3 & TQ.5A & 70 & 40 & 2800 & 357 \\
\hline 4 & TQ.6 & 80 & 45 & 3600 & 278 \\
\hline 5 & TQ.7 & 80 & 40 & 3200 & 313 \\
\hline 6 & TQ.9 & 75 & 40 & 3000 & 333 \\
\hline 7 & TQ.13 & 70 & 40 & 3200 & 357 \\
\hline
\end{tabular}

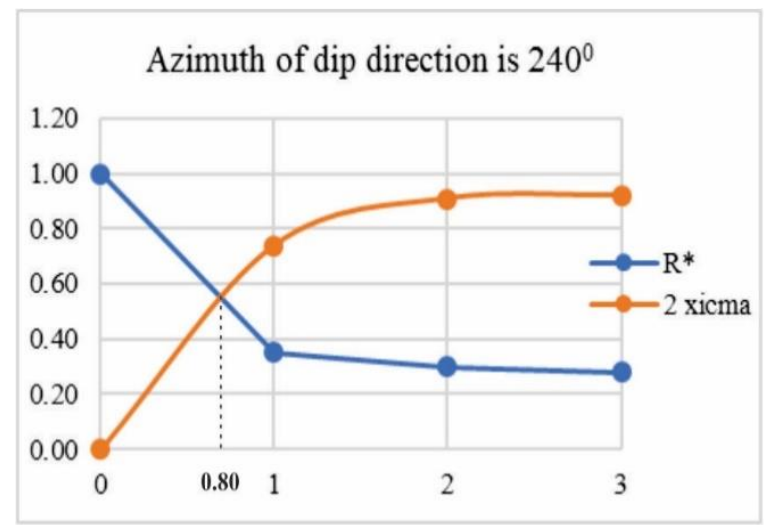

$\mathrm{h}=0.80, \mathrm{H}=32 \mathrm{~m}$

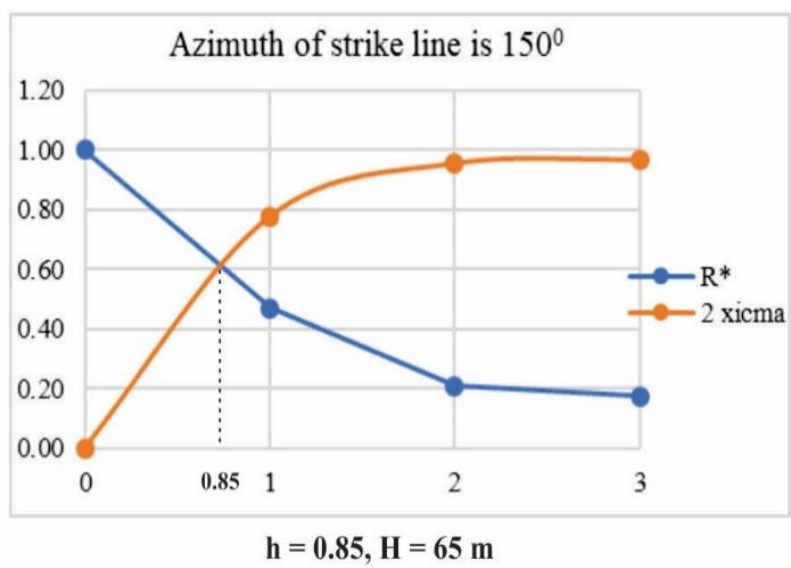

Figure 2. Autocorrelation plots $R(h)$ of the TQ.5 orebody calculated following dip direction and strike line.

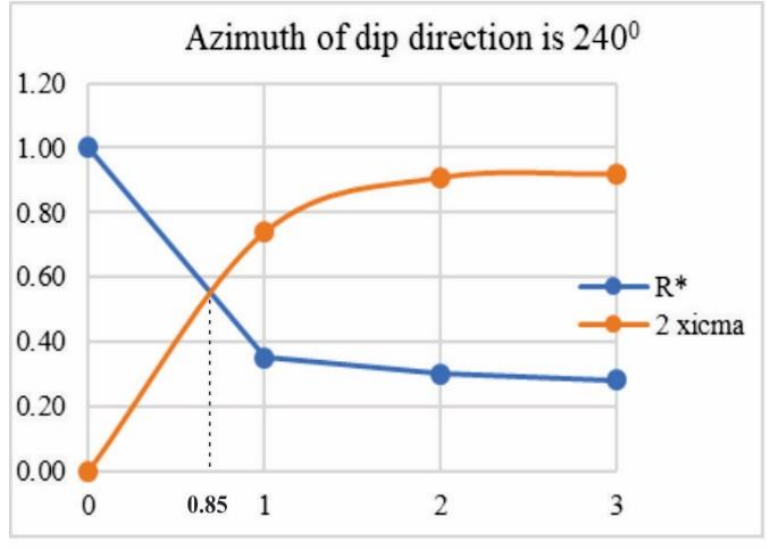

$\mathrm{h}=0.85, \mathrm{H}=34 \mathrm{~m}$

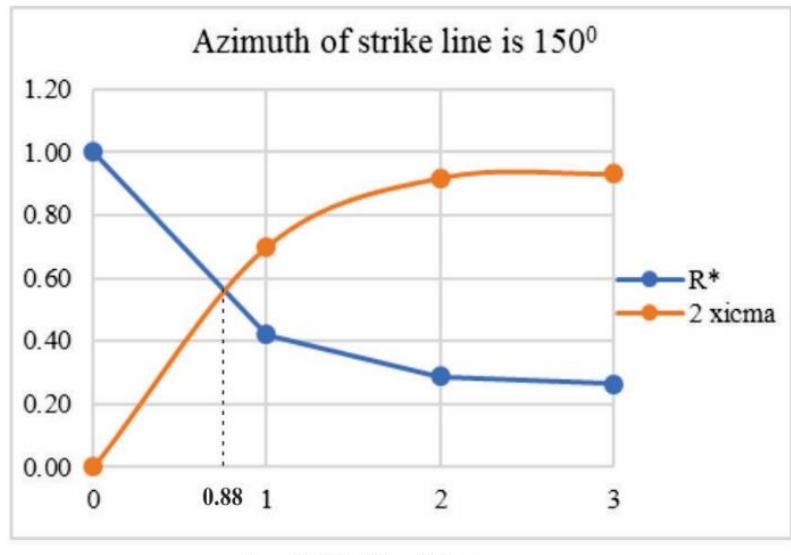

$\mathrm{h}=0.88, \mathrm{H}=70 \mathrm{~m}$

Figure 3. Autocorrelation plots R(h) of the TQ.6 orebody calculated following dip direction and strike line. 

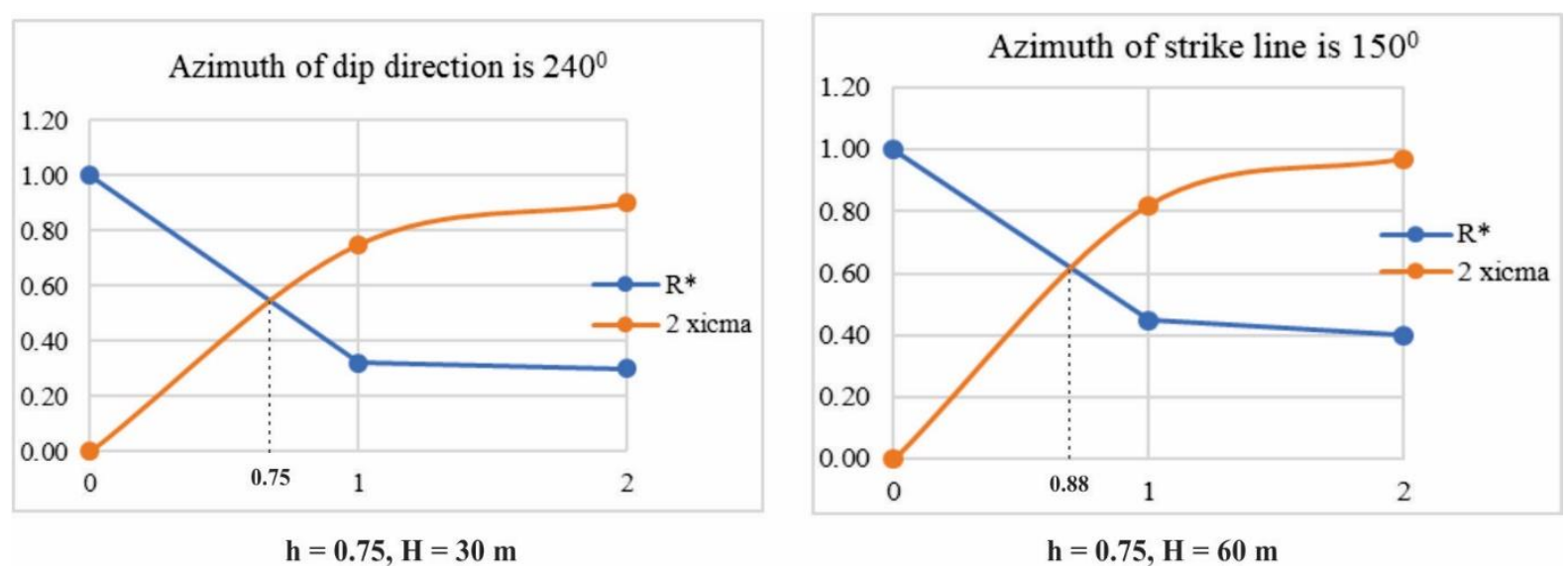

Figure 4. Autocorrelation plots R(h) of the TQ.13 orebody calculated following dip direction and strike line.

Table 8. The density of exploration grid based on the theory of stable random function.

\begin{tabular}{|c|c|c|c|c|c|}
\hline Orebody & $\begin{array}{c}\text { Anisotropy } \\
\text { index }\end{array}$ & \multicolumn{2}{|c|}{ Distance (meter) } & $\begin{array}{c}\text { Density } \\
\text { (square meter) }\end{array}$ & $\begin{array}{c}\text { Number of exploration } \\
\text { works } / \mathrm{km}^{2}\end{array}$ \\
\hline TQ.5 & 0.47 & 68 & 32 & 2176 & 460 \\
\hline TQ.6 & 0.49 & 70 & 34 & 2380 & 420 \\
\hline TQ.13 & 0.46 & 60 & 30 & 1800 & 556 \\
\hline
\end{tabular}

Table 9. Exploration grid determined for reserve level 122.

\begin{tabular}{|c|c|c|c|}
\hline \multirow{2}{*}{ Orebody } & \multicolumn{2}{|c|}{ Distance (meter) } & \multirow{2}{*}{ Number of exploration works $/ \mathrm{km}^{2}$} \\
\cline { 2 - 3 } & Flowing strike line & Following dip direction & 408 \\
\hline TQ.5 & $70 \div 75$ & $35 \div 45$ & 408 \\
\hline TQ.6 & $70 \div 80$ & $35 \div 45$ & 556 \\
\hline TQ.13 & $60 \div 70$ & $30 \div 40$ & $408 \div 556$ \\
\hline General grid & $60 \div 80$ & $30 \div 40$ & \\
\hline
\end{tabular}

\section{Conclusions}

Research results show that lead-zinc orebodies in Ban Lim area are mainly lensshaped, fully distributed in the layered surfaces of dolomitized limestone of the Coc Xo formation. Average lead-zinc contents in the orebodies have varied from $3.27 \%$ to $8.33 \%$; its coefficient of variation $(V c)$ is in the range from $13.71 \%$ (evenly) to $137.92 \%$ (very unevenly); most of them can be inductive to the normal standard distribution. The average thickness of lead-zinc bodies is in a range from $0.92 \mathrm{~m}$ to $6.48 \mathrm{~m}$; its coefficient of variation $(\mathrm{Vm})$ is in the range from $8.7 \%$ (stable) to $132.95 \%$ (very unstable).

From quantitative calculation results and in comparison with the Decision of the Vietnam Ministry of Natural Resources and Environment (06/2006/QD-BTNMT), the authors have decided to categorize Ban Lim lead-zinc deposit to group
III deposits. For the exploration of this type of minerals, it is recommended to use the linear grid pattern. Appropriate exploration grid pattern for category 122 reserve is $(60 \div 80) \mathrm{m} \times(30 \div 40) \mathrm{m}$. It means that the line spacing of the exploration grid is selected to be $80 \mathrm{~m}$ or even better $60 \mathrm{~m}$, and the spacing between the points to be $40 \mathrm{~m}$ or even better $30 \mathrm{~m}$. These calculated results are welldocumented foundations that allow suggesting a mining group of deposit and an exploration grid pattern for lead-zinc ore in Ban Lim area and other regions occurring in similar geological settings.

\section{References}

Do Quoc Binh (ed.), 2004. Report on the prospective setting of lead-zinc, gold, and accompanying minerals in Phia Da - Na Cang area. Vietnam Institute of Geosciences and Mineral resources (in Vietnamese). 
Kazdan, A.B., 1977. Prospecting and exploration of mineral deposits. Nedra Publishers, Moscow (in Russian).

Nguyen Van Phu (ed.), 2019. Report on exploration of lead-zinc deposit in Ban Lim area, Thai Hoc village, Bao Lam district and Son Lo village, Bao Lac district, Cao Bang province. Dong Bac Geological Division (in Vietnamese).

Nguyen Van Tuong, 2018. Research on mining group setting and exploration grid for lead zinc ore type in Ban Lim area, Cao Bang province. Unpublished master thesis. Hanoi University of Mining and Geology (in Vietnamese).

Phung Quoc Tri (ed.), 2013. Report on the prospective evaluation of lead-zinc ores in Ban Lim - Phi Dam area, Cao Bang - Bac Kan province. General Department of Geology and
Minerals of Vietnam (in Vietnamese).

Pogrebiski, E.O., 1973. Prospecting and exploration of mineral deposits. Nedra Publishers. Moscow (in Russian).

Saikia, K., Sarkar, B.C., 2006. Exploration drilling optimization using geostatistics: a case in Jharia Coalfield, India. Applied Earth Science 115(1). 13-25.

Vietnam Ministry of Natural Resources and Environment, 2006. The decision of Promulgating the Regulation on the classification of solid-mineral deposits and resources (Number: 06/2006/QĐ-BTNMT), Ha Noi, June 07, 2006 (in Vietnamese).

Wellmer, F.W., 1998. Statistical evaluations in exploration for mineral deposits. Springer Verlag Berlin Heidelberg. Printed in Germany. 